\title{
Papers
}

\section{Incidence of fires and related injuries after giving out free smoke alarms: cluster randomised controlled trial}

\author{
Carolyn DiGuiseppi, Ian Roberts, Angie Wade, Mark Sculpher, Phil Edwards, Catherine Godward, \\ Huiqi Pan, Suzanne Slater
}

\begin{abstract}
Objective To measure the effect of giving out free smoke alarms on rates of fires and rates of fire related injury in a deprived multiethnic urban population. Design Cluster randomised controlled trial.

Setting Forty electoral wards in two boroughs of inner London, United Kingdom.

Participants Primarily households including elderly people or children and households that are in housing rented from the borough council.

Intervention 20050 smoke alarms, fittings, and educational brochures distributed free and installed on request.

Main outcome measures Rates of fires and related injuries during two years after the distribution; alarm ownership, installation, and function.

Results Giving out free smoke alarms did not reduce injuries related to fire (rate ratio $1.3 ; 95 \%$ confidence interval 0.9 to 1.9 ), admissions to hospital and deaths (1.3; 0.7 to 2.3 ), or fires attended by the fire brigade (1.1; 0.96 to 1.3$)$. Similar proportions of intervention and control households had installed alarms (36/119 $(30 \%)$ v 35/109 (32\%); odds ratio 0.9; $95 \%$ confidence interval 0.5 to 1.7$)$ and working alarms (19/118 (16\%) $v 18 / 108$ (17\%); $0.9 ; 0.4$ to 1.8 ).

Conclusions Giving out free smoke alarms in a deprived, multiethnic, urban community did not reduce injuries related to fire, mostly because few alarms had been installed or were maintained.
\end{abstract}

\section{Introduction}

Residential fires caused 466 deaths and 14600 non-fatal injuries in the United Kingdom in 1999. ${ }^{1}$ The risk of death from fire is associated with socioeconomic class, ${ }^{2}$ partly because of social differences in the risk factors for fires and in ownership of smoke alarms. The risk of death in a house fire is three times higher in homes without smoke alarms. ${ }^{3}$ A controlled study before and after distribution of free smoke alarms to households in one area at high risk in Oklahoma City, United States, showed an $80 \%$ drop in hospitalisations and deaths related to fire, while morbidity and mortality related to fire in the rest of the city did not change, ${ }^{4}$ but these findings may not apply in other settings.

No randomised controlled trials have evaluated the benefits of distributing free alarms. ${ }^{5}$ To quantify the effect of giving out free smoke alarms on fires and related injuries, we conducted a cluster randomised controlled trial in a deprived multiethnic urban population.

\section{Methods}

The study took place in two inner London boroughs with a total of 330000 residents, of whom $51 \%$ (168 300) lived in council or other social housing and $18 \%$ were from a minority ethnic group. The mean Jarman score, a measure of material deprivation and increased healthcare needs, ${ }^{67}$ was more than two standard deviations greater than the national mean.

\section{Study design and randomisation}

We conducted a cluster randomised controlled trial in the 40 electoral wards that had Jarman scores at least one standard deviation greater than the national mean. The other six wards were excluded. The studied wards contained between 2179 and 5586 (mean 3686) households and between 5205 and 12661 (8191) residents. We randomised by ward in order to evaluate an area-wide distribution like that conducted in Oklahoma City and to reduce contamination between intervention and control households. ${ }^{4}$

To reduce potential confounding by socioeconomic status and use of health care, wards were pair matched by Jarman score. An independent statistician randomly allocated each ward of a pair to the intervention or control group, using a computer generated list of random numbers.

\section{Intervention}

Details of the intervention are published elsewhere. ${ }^{8}$ In coordination with the local health authority, the programme distributed 20050 smoke alarms, with batteries, fittings, and fire safety brochures (in English, Bengali, and other local languages), to 19950 households, door to door, between July 1997 and January 1998, targeted to households at high risk. ${ }^{8}$ We aimed to provide alarms to $25 \%$ of intervention households (the same proportion as in Oklahoma City), ${ }^{4}$ to increase local alarm ownership from $47 \%$ to the national average of $72 \% .{ }^{910}$ Free installation was offered. One year later, postcards reminding that the battery should be changed were sent. Control wards received no intervention.
Editorial by Pless

Department of Preventive Medicine and Biometrics,

University of

Colorado Health

Sciences Center,

Campus Box B-119,

Denver, CO 80262 .

USA

Carolyn DiGuiseppi associate professor

London School of Hygiene and

Tropical Medicine, London

WC1B 3DP

Ian Roberts

professor

Phil Edwards

research fellow

Centre for

Paediatric

Epidemiology and

Biostatistics,

Institute of Child

Health, University

College London,

London

WC1N 1EH

Angie Wade

senior lecturer

Catherine Godward

research fellow

Huiqi Pan

research fellow

Centre for Health Economics,

University of York,

York YO1 5DD

Mark Sculpher

professor

Department of

Public Health,

Camden and

Islington Health

Authority, London

NW1 1LJ

Suzanne Slater

public health project

officer

Correspondence to:

C DiGuiseppi

Carolyn.DiGuiseppi@

uchsc.edu

bmj.com 2002;325:995 


\section{Outcome measures}

The primary outcome was the incidence of injury related to fire resulting in attendance at an emergency department, hospitalisation, or death during the follow up period. We included any injury that resulted from fire in an occupied dwelling of a study ward. We also assessed the incidence of fires in dwellings that were attended by the fire brigade.

Outcomes were identified from data collected routinely by the local health authority, coroner, emergency departments, hospitals, and the London fire, ambulance, and helicopter services. Blinded researchers screened records and extracted data from eligible cases on injury, circumstances, and the postcode where the event occurred. Patients with incomplete or missing records were sent postal questionnaires to determine eligibility. Cases of undetermined eligibility were excluded. Data collection methods are detailed elsewhere. ${ }^{11}$

We collected data for 13 months before and 24 months after we gave away the alarms. We calculated person years at risk by using resident populations at the midpoints of baseline and follow up periods, projected from 1991 census data. We estimated household years at risk using the 1996 estimate of households projected from 1991 census data. The number of households was assumed to be the same in each period, as later projections were not available.

We planned a subgroup analysis of injuries that were independently judged (by two researchers blinded to intervention status) to be potentially preventable, had a working alarm been present-for example, smoke inhalation while the resident was asleep. Disagreements were resolved by independently repeating the rating to exclude errors, then by discussion. The $\kappa$ statistic for inter-rater reliability was 0.85 (95\% confidence interval 0.71 to 0.98 ).

We examined the prevalence of owned, installed, and working smoke alarms, 12-18 months after distribution, in a random sample of homes rented from the borough council. Council homes accounted for $41 \%$ of households in the study area, received $67 \%$ of the alarms, and formed a convenient sampling frame. At baseline, $35 \%$ of council homes had alarms. ${ }^{9}$ Using a standardised procedure, a researcher blind to the study group visited the homes and inspected and tested any alarms present. Details are published elsewhere. ${ }^{12}$

\section{Statistical analysis}

We based analyses on the original random allocation of the ward where the fire or injury occurred, regardless of whether households had received an alarm. Data analysts were blinded. Intracluster correlation coefficients, and between and within components

Table 1 Baseline characteristics of intervention and control wards. Values are means (standard deviations) ${ }^{\star}$

\begin{tabular}{lcc} 
& Intervention $(\mathbf{n}=\mathbf{2 0}$ wards) & Control $(\mathbf{n}=\mathbf{2 0}$ wards) \\
\hline Jarman score & $34.8(9.4)$ & $34.3(8.5)$ \\
\hline No of households $\dagger$ & $3670(1053)$ & $3702(781)$ \\
\hline Population $\dagger$ & $8385(2229)$ & $7998(1669)$ \\
\hline$\%$ of households with children $<5$ years $^{*}$ & $6.7(1.1)$ & $6.4(1.3)$ \\
\hline$\%$ of single parent households & & $11.6(7.1)$
\end{tabular}

*Source: London Boroughs of Camden and Islington, from 1991 census data collected by Office for National Statistics, London, UK.

†Projection from 1991 census data by the London Research Centre.

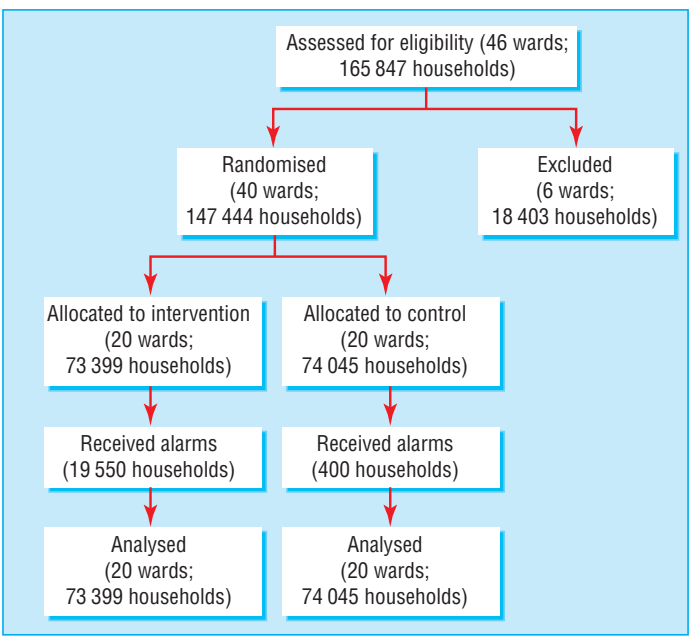

Flow of wards and households through the study

of variance, were estimated from baseline data. ${ }^{13}$ The incidence rates of each outcome were analysed using a multilevel Poisson model with pair included as a level (MLwiN v1.10.0006). ${ }^{14}{ }^{15}$ Rate ratios indicate the likelihood of each outcome in the intervention group compared to the control group, accounting for clustering by ward and matching by Jarman score, with and without adjustment for baseline rates. ${ }^{16}{ }^{17}$ Analysis with a log odds model, based on the normal distribution, gave similar results (data not shown). ${ }^{18-20}$ For alarm outcomes, we analysed logistic binomial models for distinguishable data, matching on ward and controlling for Jarman score (EGRET v1.02.10).

\section{Research ethics}

A working group, representing local government and community organisations, developed the programme. Recipients of alarms signed consent forms. The Great Ormond Street Hospital and Institute of Child Health Research Ethics Committee approved the trial.

\section{Results}

The figure shows the flow of wards and households through the trial. Of 20050 alarms distributed, we estimate $98 \%$ went to intervention households. We estimated the number of households receiving alarms from completed consent forms. ${ }^{8}$ (Control households receiving alarms were either located on ward borders and visited in error or mistakenly offered alarms at central distribution sites.) We estimate a total of $85 \%$ of recipients lived in council or other rental homes or households including elderly people or children. Installation was provided for 8\% (1640) of recipients. Table 1 shows baseline characteristics of the two groups.

\section{Injuries related to fire}

Table 2 gives the numbers of events and crude incidence rates for each outcome. We identified 384 injuries related to fire, of which $90(23 \%)$ resulted in hospitalisation and eight $(2 \%)$ in death. Rate ratios show no benefit to all injuries or to hospitalisations and deaths (table 2). Adjustment for baseline injury rates had little effect on results. Baseline intracluster correlation coefficients were 0.00016 for all injuries and 0.00012 for hospitalisations and deaths, indicating that 
Table 2 Rates of injuries related to fire, admissions to hospital, and deaths and of fires attended by the fire department in homes supplied with smoke alarms or not

\begin{tabular}{|c|c|c|c|c|c|c|}
\hline & \multicolumn{4}{|c|}{ No of events per total person years (per 100000 person years) } & \multicolumn{2}{|c|}{ Rate ratio $(95 \% \mathrm{Cl})^{*}$} \\
\hline & \multicolumn{2}{|c|}{ Intervention } & \multicolumn{2}{|c|}{ Control } & \multirow[b]{2}{*}{ Crude } & \multirow{2}{*}{$\begin{array}{c}\text { Adjusted for } \\
\text { baseline rates }\end{array}$} \\
\hline & Baseline & Follow up & Baseline & Follow-up & & \\
\hline All injuries & $66 / 181667(36.3)$ & $137 / 340275(40.3)$ & 77/173 $285(44.4)$ & $104 / 319710(32.5)$ & $1.3(0.9$ to 1.8$)$ & $1.3(0.9$ to 1.9$)$ \\
\hline Preventable injuries & $51 / 181667(28.1)$ & $100 / 340275(29.4)$ & $65 / 173285(37.5)$ & $84 / 319710(26.3)$ & $1.1(0.8$ to 1.7$)$ & $1.2(0.8$ to 1.8$)$ \\
\hline Preventable hospitalisations and deaths & 15/181 $667(8.3)$ & $19 / 340275(5.6)$ & $20 / 173285(11.5)$ & $18 / 319710(5.6)$ & $1.0(0.5$ to 1.9$)$ & $1.0(0.5$ to 2.0$)$ \\
\hline Attended firesł & $270 / 79516(339.6)$ & $524 / 147080(356.3)$ & $322 / 80215(401.4)$ & $487 / 147558(330.0)$ & $1.0(0.9$ to 1.2$)$ & $1.1(0.96$ to 1.3$)$ \\
\hline
\end{tabular}

*Rate ratios obtained from Poisson model, taking into account clustering by ward and matching by Jarman score.

fIntervention group includes one death at baseline and three during follow up; control group includes two deaths at baseline and two during follow up.

łIncidence rate of attended fires is measured in number of events per total household years (per 100000 household years).

residents within the same ward were slightly more likely to be similar with respect to their risk of injury related to fire or hospitalisation and death than were residents in different wards.

\section{Potentially preventable injuries related to fire} We judged $78 \%$ of injuries to be potentially preventable by smoke alarms (table 2). There was no evidence of a beneficial effect on preventable injuries or on preventable hospitalisations and deaths, with or without adjustment of the rate ratios for baseline rates (table 2). Intracluster correlation coefficients were 0.00017 for all potentially preventable injuries and 0.00011 for preventable hospitalisations and deaths.

\section{Fires}

The fire brigade attended 1603 residential fires in the study area (table 2). The intervention did not show a beneficial effect of intervention on attended fires before or after adjustment for baseline rates (table 2). The baseline intracluster correlation coefficient for attended fires was 0.00033 .

Smoke alarm ownership, installation, and function Of 315 eligible homes, similar proportions of intervention and control households were contacted $(82 \%$ v 79\%), surveyed (77\% $v 72 \%)$, and inspected $(75 \% v 70 \%)$. Table 3 shows baseline characteristics and results of inspection and testing.

Groups did not differ in terms of alarms present (odds ratio $1.0 ; 95 \%$ confidence interval 0.6 to 1.9 ), installed $(0.9 ; 0.5$ to 1.7$)$, or correctly installed $(0.9 ; 0.4$ to 1.7$)$. Similar proportions of households had at least one installed and working alarm $(0.9 ; 0.4$ to 1.8$)$ and at least one correctly installed and working alarm (1.0; 0.4 to 2.4).

\section{Discussion}

Giving smoke alarms away in an urban multiethnic deprived community did not reduce total or serious injuries from fires. Intervention and control households had similar proportions of installed and working alarms after the distribution; few alarms had been installed or were maintained.

Our programme mirrored the Oklahoma City programme. ${ }^{4}$ We distributed similar alarms to the same proportion of target households (27\%) and installed a similar proportion ( $8 \%$ v $9 \%$ in Oklahoma City). In Oklahoma City, however, serious injuries declined by $80 \%$ in the intervention area while they increased $8 \%$ in the control area. In our study, serious injuries declined by only $13 \%$ in intervention wards, compared with a $50 \%$ decline in control wards. The confidence intervals of our rate ratios exclude all but a modest effect on total injuries and attended fires. While we cannot exclude a clinically important, beneficial effect on serious injuries, the absence of an increase in the prevalence of installed, working alarms suggests that the apparent lack of benefit in our population is real.

The benefit in Oklahoma City may partially reflect regression to the mean, based on study design; another likely explanation for the different results is that population differences affect the likelihood of alarms being installed and maintained. Recipients may have not understood installation instructions or brochures about the benefits of alarms because of illiteracy or poor command of English. Tenants may have lacked installation skills or tools or may have worried about landlords objecting to installation. Because of the small size of some flats, incorrect installation near sources of steam or cooking smoke may have increased false or nuisance alarms, leading to removal of the battery or disconnection. ${ }^{12}$ We attempted to tackle these barriers in our programme, through use of foreign language brochures and local ethnic minority recruiters, offers of free installation, provision of pictorial information on installation, and postcards reminding recipients to change the battery. ${ }^{8}$ Nevertheless, few alarms were installed or working at follow up.

It is unlikely that restricting our survey to council homes prevented detection of a substantial increase in the number of alarms. Most of our alarms went to council residents. Even if every alarm distributed to owner occupied and privately rented homes were installed and working, the overall prevalence of working alarms in intervention wards would have been

Table 3 Household characteristics and smoke alarm ownership. Values are numbers (percentages)

\begin{tabular}{lcc}
\hline Household characteristics & Intervention & Control \\
\hline More than two years at current address & & \\
\hline Any occupant aged 65 years or older & $102 / 122(84)$ & $101 / 113(89)$ \\
\hline Any occupant aged 0-15 years & $42 / 122(34)$ & $34 / 113(30)$ \\
\hline Single parent household & $45 / 122(37)$ & $32 / 112(29)$ \\
\hline Home is flat or bedsitt & $16 / 122(13)$ & $15 / 113(13)$ \\
\hline Inspection and testing results & $107 / 120(89)$ & $105 / 111(94)$ \\
\hline At least one alarm present & & \\
\hline At least one alarm installed & $47 / 119(39)$ & $42 / 109(38)$ \\
\hline At least one alarm correctly installed & $36 / 119(30)$ & $35 / 109(32)$ \\
\hline At least one alarm installed and working $\ddagger$ & $19 / 119(16)$ & $19 / 109(17)$ \\
\hline At least one alarm correctly installed and working $\ddagger$ & $19 / 118(16)$ & $18 / 108(17)$ \\
\hline
\end{tabular}

*Defined as household with one adult and one or more children.

tIncludes maisonettes occupying two floors. A bedsit is a single room used as a bedroom and a sitting room. $\ddagger$ Łased on positive smoke test. Testing refused because of sleeping child $(n=1)$ or not possible because of ceiling height $(n=1)$ 


\section{What is already known on this topic}

In the United Kingdom, residential fires caused 466 deaths and 14600 non-fatal injuries in 1999

The risk of death from fire is associated with socioeconomic class

One study reported an $80 \%$ decline in hospitalisations and deaths from residential fires after free smoke alarms were distributed in an area at high risk, but these results may not apply in other settings, and evidence from randomised controlled trials is lacking

\section{What this study adds}

Giving out free smoke alarms in a multiethnic poor urban population did not reduce injuries related to fire or fires

Giving smoke alarms away may be a waste of resources and of little benefit unless alarm installation and maintenance is assured

only $9 \%$ higher. A high turnover of households could not explain the absence of installed alarms, since $86 \%$ of households surveyed had been at the same address for two or more years. Contamination is also an unlikely explanation. Completed consent forms showed that only $2 \%$ of alarms were distributed to control addresses. There were no media campaigns or other publicity of the programme, and nearly all alarms were distributed directly to the residents' homes. Extensive installation of alarms in both groups would have led to an increase in overall prevalence, yet the $39 \%$ of council households with alarms present was only modestly higher than the 35\% prevalence reported two years before. ${ }^{9}$

\section{Conclusions}

Widespread implementation of programmes giving away smoke alarms may waste resources and be of little benefit unless alarm installation and maintenance is assured..$^{22}$ Our results suggest that simply giving alarms to poor, urban households is unlikely to reduce injuries related to fire. We did not assess reasons that alarms were not installed or maintained in this population. We have recently identified differences in long term function according to type of alarm and characteristics of households. ${ }^{23}$ We are currently evaluating differences in long term function among different types of alarms, and attitudes towards and knowledge about fire safety and smoke alarms and how these might affect the installation and maintenance of alarms, to help learn how best to increase installed and working alarms in populations at high risk.

We thank the Camden and Islington Accident Prevention Alliances; Homerton, Royal Free, Royal London, Queen Elizabeth, St Mary's (Paddington), University College, and Whittington Hospitals; Mount Vernon Hospital Burns Unit; London Fire Brigade; London Ambulance and Helicopter Emergency
Medical Services; Her Majesty's Coroner's Court, St Pancras; David Dunn; Tracy Greenidge; Mark McCarthy; Sarah Pratap; Norma Speirs; community representatives who distributed alarms; and tenants who participated in our survey. The study alarms were purchased from Dicon Safety Products (UK) and BRK Brands Europe. Population projections from census data are by the London Research Centre. The trial ISRCTN is 32449631 .

Contributors: CD, IR, AW, MS, SS, CG, PE, and Mark McCarthy contributed to study conception and design. SS oversaw programme implementation. CG, Tracy Greenage, and Norma Speirs collected data. AW, HP, CD, IR, and PE analysed and interpreted results. CD drafted the manuscript. All authors revised the manuscript critically for intellectual content and approved the final version. $\mathrm{CD}$ and IR are guarantors.

Funding: Medical Research Council, with additional funding from the Home Office (Fire Research and Development Group and National Community Fire Safety Centre), Department of Health (Health Promotion Division), Camden and Islington Councils, the British Medical Association, and the Camden and Islington Health Authority.

Competing interests: None declared.

1 Watson L, Gamble J, Schofield R. Fire statistics: United Kingdom 1999. London: Government Statistical Service, November 2000. (Home Office Statistical Bulletin Issue 20/00.)

2 Roberts I, Power C. Does the decline in child injury mortality vary by social class? A comparison of class specific mortality in 1981 and 1991. BMJ 1996;313:784-6.

3 Runyan CW, Bangdiwala SI, Linzer MA, Sacks JJ, Butts J. Risk factors for fatal residential fires. N Engl J Med 1992;327:859-63.

4 Mallonee S, Istre GR, Rosenberg M, Reddish-Douglas M, Jordan F, Silverstein P, et al. Surveillance and prevention of residential-fire injuries. N Engl J Med 1996;335:27-31.

5 DiGuiseppi C, Higgins JPT. Systematic review of controlled interventions to promote smoke alarms. Arch Dis Child 2000;82:341-8.

6 Jarman B. Identification of underprivileged areas. BMJ 1983;286:1705-9.

7 Jarman B. Underprivileged areas: validation and distribution of scores. BMJ 1984;289:1587-92.

8 DiGuiseppi C, Slater S, Roberts I, Adams L, Sculpher M, Wade A, et al. The "Let's get alarmed!" initiative: a smoke alarm giveaway programme. Inj Prev 1999;5:177-82.

9 Adams L, DiGuiseppi C. A population-based survey to estimate the prevalence of ownership and maintenance of smoke alarms in two inner London boroughs. Int J Health Promot Educ 1999;37:65-7.

10 Roberts I. Smoke alarm use: prevalence and household predictors. Inj Prev 1996;2:263-5.

11 DiGuiseppi C, Edwards P, Godward C, Roberts I, Wade A. Urban residential fire and flame injuries: a population-based study. Inj Prev 2000;6:250-4.

12 DiGuiseppi C, Roberts I, Speirs N. Smoke alarm installation and function in inner London council housing. Arch Dis Child 1999;81:400-3.

13 Okoumunne OC, Gulliford MC, Chinn S, Sterne JAC, Burney PGJ. Methods for evaluating area-wide and organisation-based interventions in health and health care: a systematic review. Health Technol Assess (Rockv) 1999;3(5):21-32.

14 Goldstein H. Multilevel statistical models: internet edition. London: Arnold, 1999. (Kendall's Library of Statistics 3.)

15 Rasbash J, Browne W, Goldstein H, Yang M, Plewis I, Healy M, et al. A user's guide to MLwiN. London: University of London Institute of Education, 2000.

16 Duffy SW, South MC, Day NE. Cluster randomization in large public health trials: the importance of antecedent data. Stat Med 1992;11:30716.

17 Omar RZ, Thompson SG. Analysis of a cluster randomized trial with binary outcome data using a multi-level model. Stat Med 2000;19:267588.

18 Thompson SG, Pyke SD, Hardy RJ. The design and analysis of paired cluster randomized trials: an application of meta-analysis techniques. Stat Med 1997;16:2063-79.

19 Turner RM, Omar RZ, Yang M, Goldstein H, Thompson SG. A multilevel model framework for meta-analysis of clinical trials with binary outcomes. Stat Med 2000;19:3417-32.

20 Turner RM, Omar RZ, Yang M, Goldstein H, Thompson SG. Random effects meta-analysis of trials with binary outcomes using multilevel models in MLwiN. Multilevel Modelling Newsletter 1999;11(1):6-9.

21 Marriott MD. Reliability and effectiveness of domestic smoke alarms. London: Home Office Fire Research and Development Group, 1994. (Research report No 58.)

22 Shults RA, Sacks JJ, Briske LA, Dickey PH, Kinde MR, Mallonee S, et al. Evaluation of three smoke detector promotion programs. Am J Prev Med 1998;15:165-71.

23 Rowland D, DiGuiseppi C, Roberts I, Curtis K, Roberts H, Ginnelly L, et al. Prevalence of working smoke alarms in local authority inner city housing: randomised controlled trial. BMJ 2002;325:998-1001 (Accepted 15 April 2002) 